\title{
Refractory chylothorax due to thoracic duct stenosis in Noonan syndrome with RIT1 gene mutation: a case report and literature review
}

\author{
Lei yang ${ }^{1}$, Ying guo ${ }^{1}$, Xinyi $\mathrm{Xu}^{1}$, Xu Zhang ${ }^{1}$, Wei Gao ${ }^{1}$, and tingliang liu ${ }^{1}$ \\ ${ }^{1}$ Shanghai Children's Medical Center, Shanghai Jiao Tong University School of Medicine
}

March 18, 2021

\begin{abstract}
The occurrence of Noonan with refractory chylothorax with RIT1 gene mutation is very rare. The right lymphatic vessel and thoracic duct were compressed by the surrounding tissue, resulting in obstruction. After releasing the surrounding tissue, the chylothorax disappeared.
\end{abstract}

Refractory chylothorax due to thoracic duct stenosis in Noonan syndrome with RIT1 gene
mutation: a case report and literature review Introduction

Noonan syndrome (NS) [Mendelian inheritance in man (MIM) \# 163950] is a common autosomal dominant disease, with an estimated incidence rate of $1 / 1,000$ to $1 / 2,500$ live births ${ }^{1}$. It is characterized by obvious facial features, short stature, and congenital heart defects, mild to moderate developmental retardation/learning disabilities, skeletal abnormalities, cryptorchidism and myeloproliferative diseases ${ }^{2}$. It is an autosomal dominant disease with complete penetrance but variable expressiveness. About $50 \%$ of patients with NS have missense mutations in protein tyrosine phosphatase non-receptor type 11 (PTPN11) gene, with less mutations in SOS1, RAF1 and KRAS genes, accounting for 13\%,10\% and less than $5 \%$ respectively ${ }^{3}$. About $30 \%$ of patients with clinically confirmed NS are still negative ${ }^{4}$. Intractable chylothorax in childhood is a rare and potentially life-threatening disease, with an incidence rate of about 1:30,000 ${ }^{5}$. Associations with genetic syndromes include congenital lymphoid malformation syndromes such as Gorham-Stout, Optiz G/BBB, Hennekam, Milroy and NS, as well as chromosomal abnormalities such as Trisomy 21 or Turner syndrome $^{6}$. Up to now, there is no reports about the refractory chylothorax due to thoracic duct stenosis in NS with RIT1 gene mutation.

\section{Case Report}

An 8-year-old girl born in the Yunnan Province of China was admitted to the department of internal medicinecardiovascular, Shanghai Children's Medical Center, Shanghai Jiao Tong University School of Medicine in June 2020 with chief complaints of 7 years after the operation of congenital heart disease (atrial septal defect, pulmonary valve stenosis and patent ductus arteriosus), lower limb edema for more than 4 years. She was the first-born child to her parents and was born at 38 weeks and 4 days of gestation after an unremarkable pregnancy. No obvious abnormalities were found during her neonatal period. The patient had no family history of NS or chylothorax.

More than 7 years ago, the repair of atrial septal defect, correction of pulmonary valve stenosis, aortic widening and patent ductus arteriosus occlusion was performed (details unknown). More than 4 years ago, 
there was no obvious inducement for left lower limb edema. At the beginning of the disease, the knee was obvious, and then the swelling gradually spread to the right lower limb and perineum. There was no skin flush, lower limb pain, eyelid edema, and groundless sitting breathing. After standing and walking for a long time, the lower limb edema was obvious. She once visited the outpatient department of local hospital, and was suggested to wear elastic stockings, but the lower limbs still had repeated edema after wearing elastic stockings. The patients were treated with continuous right thoracic closed drainage, chylous meal. Because the cause of chylothorax was not clear, there were still lower extremity edema.

General physical examination revealed the heart rate was 100 beats/min, the heart rate was even and the heart sound was strong. $2 / 6$ systolic murmur was heard between 2-3 intercostal of left sternum. The abdomen was flat and soft. The lower edge of the liver was $2 \mathrm{~cm}$ below the ribs, soft in texture and clear in boundary. There was no depression edema in the left lower limb, obvious in leg and ankle joint, no tenderness. Edema of perineum. After admission, the thoracic drainage fluid was $610 \mathrm{ml}$ at most and $110 \mathrm{ml}$ at least every day, which was light chylous. The results of laboratory tests are shown in Tab.1.

During the operation in other hospitals, it was found that the right lymphatic vessel and thoracic duct were compressed by the surrounding tissue, resulting in obstruction. After releasing the surrounding tissue, the obstruction was relieved and chylothorax disappeared.

\section{Literature review and Discussion}

NS is a hereditary multisystem disease, which is characterized by obvious facial features, growth retardation, learning difficulties, short stature, congenital heart disease, renal abnormalities, and lymphatic malformations and bleeding difficulties ${ }^{7}$. The incidence rate of NS is estimated to be between 1:1000 and 1:2500 live births ${ }^{8}$. The most common congenital heart disease is pulmonary valve stenosis with dysplastic leaflets $(50 \%-62 \%)^{1}$. Hypertrophic obstructive cardiomyopathy with asymmetric septal hypertrophy accounted for $20 \%{ }^{1}$. Atrial septal defect is present in 6\%-10\% of patients, ventricular septal defect occurs in $5 \%$, persistent ductus arteriosus accounted for $3 \%^{1}$. Other congenital heart defects more common in NS are atrioventricular canal defects associated with sub-aortic obstruction and abnormal mitral valve structure ${ }^{2}$. In this case, the patient had pulmonary valve, atrial septal defect stenosis and patent ductus arteriosus, and the genetic diagnosis was confirmed (Fig. 1).

In NS, the affected individuals always have normal chromosome studies. Molecular genetic analysis showed that $50 \%$ of the affected individuals had pathogenic variants of PTPN11, with SOS1 accounting for approximately $13 \%$, RAF1 and RIT1 each accounting for 5\%, KRAS less than 5\%, BRAF, LZTR1, MAP2K1 and NRAS less than $1 \%^{4}$. This case is a mutation of RIT1 gene in c.246T > A, p.Phe82Leu (Fig. 1). RIT1 is located in chromosome 1q22 and consists of six exons ${ }^{9}$. Compared with the typical Noonan phenotype associated with PTPN11 mutation, patients with RIT1 mutation had less growth retardation and were more susceptible to cardiomyopathy ${ }^{10}$. RIT1 belongs to RAS superfamily of low molecular weight GTP binding proteins ${ }^{11}$. It acts as a molecular switch of guanine nucleotide regulation in cells by changing between active GTP binding state and inactive GDP binding state ${ }^{10}$. RIT1 is expressed in many tissues and throughout development ${ }^{11}$. It shares about $50 \%$ sequence homology with RAS, has additional N-terminal extension, and does not have C-terminal CAAX motif, a specific motif for post-translational modification ${ }^{9}$. So far, the reported NS related RIT1 mutations specifically affect codons 57, 82 and 95, and lead to amino acid changes in switch I and II regions ${ }^{11}$. These two protein motifs are involved in the binding of nucleotides, effectors and regulators to ensure the molecular function of RIT $1^{12}$. In this report, the identified RIT1 mutation (c.246T $>$ A, p.Phe82Leu) encodes a change in the switch II region, which is a conserved position among species and corresponds to RAS ${ }^{12}$. This RIT1 mutation showed significant high ELK1 transactivation ${ }^{13}$. Previous studies have shown that enhanced ELK transactivation has been observed in NIH3T3 cells, which express RAF1 mutations in NS patients ${ }^{14}$.

Chylothorax is a rare case of obstruction or interruption of lymphatic drainage in the lower body and gastrointestinal tract ${ }^{5}$. Lymphoid diseases are sometimes associated with Turner, Noonan, and Trisomy 21 and Elles danlo syndrome ${ }^{15}$. Chylothorax is characterized by lymph nodes containing triglycerides and 
chylous granules in the pleural cavity ${ }^{16}$. When the triglyceride level is higher than $1.24 \mathrm{mmol} / \mathrm{L}(110 \mathrm{mg}$ $/ \mathrm{dl}$ ), the diagnosis is confirmed ${ }^{16}$. In this case, the concentration of triglyceride in pleural effusion was 2.62 mmol / L, and chyle was positive in pleural effusion (Fig. 2 and Tab. 1). The thoracic duct enters the thoracic cavity through the diaphragm esophageal hiatus ${ }^{17}$. It starts from outside the pleura of the posterior mediastinum to the right side of the spine, between the azygos vein and the descending aorta, near the esophagus and pericardium, and finally to the left jugular vein and subclavian vein before the subclavian artery, vertebral artery and thyroid carotid artery trunk ${ }^{17}$. There may be many anatomical variations in various parts of the thoracic duct. The operation proved that the thoracic duct stenosis was compressed by surrounding tissue. Chylothorax was cured after removing obstruction.

To the best of our knowledge, this report of ours depicting the refractory chylothorax due to thoracic duct stenosis in a case of NS with RIT1 gene mutation, is the first in English literature.

Figure 1: Gene sequencing test report

According to the literature, RIT1 gene mutation can cause Noonan syndrome and other diseases// www.omim.org/entry/609591 )Most of them are autosomal dominant. The mutation c.246t $>$ A and p.Phe82leu in this sample are newly found (not included in HGMD and gnomAD databases, gnomAD: all: $0.000 \%$ ), which are located in the known hot spot mutation region. According to the classification standard of ACMG mutation, they can be classified as "pathogenic" mutation.

Figure 2 Chest X-ray

Large heart shadow, right lower lung exudation, right pleural effusion

Table 1 Hydrothorax examination

\section{References}

1. Yart A, Edouard T. Noonan syndrome: an update on growth and development. Curr Opin Endocrinol Diabetes Obes. 2018 Feb; 25(1):67-73.

2. Bhambhani V, Muenke M. Noonan syndrome. Am Fam Physician. 2014 Jan 1; 89(1):37-43.

3. Roberts AE, Allanson JE, Tartaglia M, Gelb BD. Noonan syndrome. Lancet. 2013 Jan 26; 381(9863):33342 .

4. Ziegler A, Loundon N, Jonard L, Cavé H, Baujat G, Gherbi S, Couloigner V, Marlin S. Noonan Syndrome: An Underestimated Cause of Severe to Profound Sensorineural Hearing Impairment. Which Clues to Suspect the Diagnosis? Otol Neurotol. 2017 Sep; 38(8):1081-1084.

5. Novelli PM, Chan EG, Frazier AA, Villa Sanchez M. Interventional Therapies for Thoracic Duct Injury and Intractable Chylothorax.J Thorac Imaging. 2019 Jul; 34(4):258-265.

6. Shimakawa T, Naritaka Y, Miyazawa M, Asaka S, Shimazaki A, Yamaguchi K, Yokomizo H, Yoshimatsu K, Shiozawa S, Katsube T. Lymphangiography Was Useful in Postoperative Intractable Chylothorax after Surgery for Esophageal Cancer: A Case Report. J Nippon Med Sch. 2017; 84(6):268-273.

7. Turner AM. Noonan syndrome. J Paediatr Child Health. 2014 Oct; 50(10):E14-20.

8. van der Burgt I. Noonan syndrome. Orphanet J Rare Dis. 2007 Jan 14; 2:4.

9. Castel P, Cheng A, Cuevas-Navarro A, Everman DB, Papageorge AG, Simanshu DK, Tankka A, Galeas J, Urisman A, McCormick F. RIT1 oncoproteins escape LZTR1-mediated proteolysis. Science. 2019 Mar 15; 363(6432):1226-1230.

10. Kouz K, Lissewski C, Spranger S, Mitter D, Riess A, Lopez-Gonzalez V, Lüttgen S, Aydin H, von Deimling F, Evers C, Hahn A, Hempel M, Issa U, Kahlert AK, Lieb A, Villavicencio-Lorini P, BallestaMartinez MJ, Nampoothiri S, Ovens-Raeder A, Puchmajerová A, Satanovskij R, Seidel H, Unkelbach S, 
Zabel B, Kutsche K, Zenker M. Genotype and phenotype in patients with Noonan syndrome and a RIT1 mutation. Genet Med. 2016 Dec; 18(12):1226-1234.

11. Cavé H, Caye A, Ghedira N, Capri Y, Pouvreau N, Fillot N, Trimouille A, Vignal C, Fenneteau O, Alembik Y, Alessandri JL, Blanchet P, Boute O, Bouvagnet P, David A, Dieux Coeslier A, Doray B, Dulac O, Drouin-Garraud V, Gérard M, Héron D, Isidor B, Lacombe D, Lyonnet S, Perrin L, Rio M, Roume J, Sauvion S, Toutain A, Vincent-Delorme C, Willems M, Baumann C, Verloes A. Mutations in RIT1 cause Noonan syndrome with possible juvenile myelomonocytic leukemia but are not involved in acute lymphoblastic leukemia. Eur J Hum Genet. 2016 Aug; 24(8):1124-31.

12. Aoki Y, Niihori T, Inoue S, Matsubara Y. Recent advances in RASopathies. J Hum Genet. 2016 Jan; 61(1):33-9.

13. Aoki Y, Niihori T, Banjo T, Okamoto N, Mizuno S, Kurosawa K, Ogata T, Takada F, Yano M, Ando T, Hoshika T, Barnett C, Ohashi H, Kawame H, Hasegawa T, Okutani T, Nagashima T, Hasegawa S, Funayama R, Nagashima T, Nakayama K, Inoue S, Watanabe Y, Ogura T, Matsubara Y. Gain-of-function mutations in RIT1 cause Noonan syndrome, a RAS/MAPK pathway syndrome. Am J Hum Genet. 2013 Jul 11; 93(1):173-80.

14. Nihori T, Nagai K, Fujita A, Ohashi H, Okamoto N, Okada S, Harada A, Kihara H, Arbogast T, Funayama R, Shirota M, Nakayama K, Abe T, Inoue SI, Tsai IC, Matsumoto N, Davis EE, Katsanis N, Aoki Y. Germline-Activating RRAS2 Mutations Cause Noonan Syndrome. Am J Hum Genet. 2019 Jun 6; 104(6):1233-1240.

15. Attar MA, Donn SM. Congenital chylothorax. Semin Fetal Neonatal Med. 2017 Aug; 22(4):234-239.

16. Tutor JD. Chylothorax in infants and children. Pediatrics. 2014 Apr; 133(4):722-33.

17. García J, Alemán C, Jáuregui A, Vázquez A, Persiva Ó, Fernández de Sevilla T. Chylothorax in Adults. Characteristics of 17 Patients and a Review of the Literature. Arch Bronc Chylothorax in Adults. Characteristics of 17 Patients and a Review of the Literature. Arch Bronconeumol. 2017 Jul; 53(7):407-408.

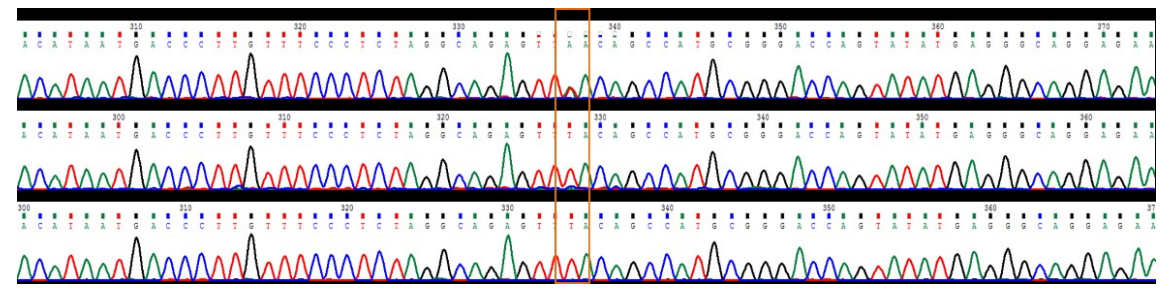




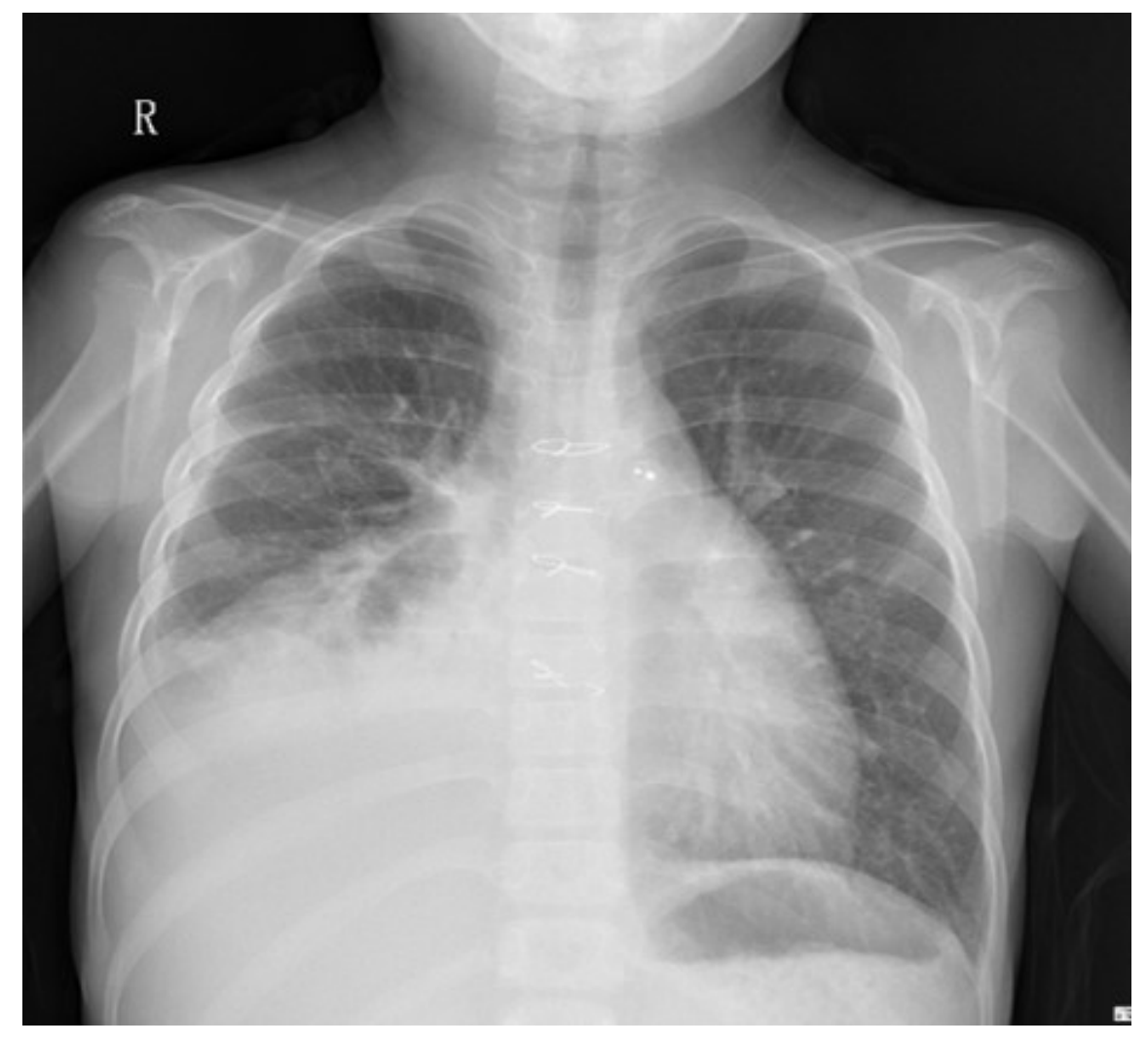

